\title{
Innovations in publication: free sharing of all Biophysical Reviews' content
}

\author{
Damien Hall $^{1,2}$
}

Received: 15 February 2017 / Accepted: 3 March 2017 / Published online: 20 March 2017

(C) International Union for Pure and Applied Biophysics (IUPAB) and Springer-Verlag Berlin Heidelberg 2017

Every working scientist has experienced a situation similar to the following at least once in their career: You have written a fantastic paper or review article and yet, the recognition your work receives in terms of crediting citations, seems to be in no way commensurate with your perceived quality of that work. Then, another paper is published by a different group, which essentially makes points identical to those in your earlier work, but this newer paper is cited at a wildfire rate.

Such differential transmission of similar content is the cornerstone of inefficient market theory, a subject that defines our modern physical understanding of economics (Shiller 2014). In short, the inefficient market model dictates that quality is only one factor defining the degree of saleability of an item, with ease of access, exuberance of the market and the psychology of advertising (or group thinking) often being just as important features in achieving these goals (Lawrence 2007). Despite the apparent unfairness, researchers need to be cognizant of the fact that their scientific success, in the short term at least, may depend as much (or more) on product placement and scientific 'advertisement' than any actual measure of intrinsic scientific worth (Lawrence 2007). With this point in mind, it is important to researchers' career progression for them to try and maximise the dissemination of published work. In this Editorial, I describe a Springer Nature initiative

Damien Hall

damien.hall@anu.edu.au; damien.hall@protein.osaka-u.ac.jp

1 Institute for Protein Research, Osaka University, 3-1 Yamadaoka, Suita, Osaka 565-0871, Japan

2 Research School of Chemistry, Australian National University, Acton, ACT 2601, Australia known as 'SharedIt' that helps to promulgate scientists' research work published within Biophysical Reviews.

In its most basic form, the SharedIt initiative constitutes a web link to the ReadCube web domain that specifies a readonly portable document format (PDF) version of the author's article. Upon publication of an article in Biophysical Reviews, the corresponding author will receive a SharedIt link by automated email, while the non-corresponding authors of the paper may enter their article's digital object identifier (DOI) number and email address into the following Springerhosted web site, http://authors.springernature.com/share.

A short time later, the author will receive a reply email of the following form:

Dear Author,

Thank you for publishing your manuscript with Biophysical Reviews. To assist you in sharing your published article swiftly with colleagues and the wider community, we are providing you with the special SharedIt link below. Anyone with the link will be able to connect to a view-only version of your article for free. If you have selected an Open Access option for your paper, or where an individual can view content via a personal or institutional subscription, recipients of the link will also be able to download and print the PDF. All readers of your article via the shared link will also be able to use Enhanced PDF features such as annotation tools, oneclick supplements, citation file exports and article metrics.

http://rdcu.be/pcs1

Please feel free to share this link with your co-authors. There are no restrictions on the number of people you may share this link with, how many times they can view the linked article or where you can post the link online.

More information on Springer Nature's commitment to content sharing and the SharedIt initiative is available here.

Sincerely,

Springer Nature 
The most rudimentary application of the SharedIt web link would involve its posting on the author's website or its provision via reply email, as for an old-school type of reprint article request between reader and author. However, unlike a simple PDF file, the SharedIt web link is free to be posted literally anywhere, at any time, in a manner that would violate standard copyright agreements if it pertained to actual physical posting or placement of the journal-produced PDF copy of the paper. It is this ability for free posting that signals the real power of the SharedIt initiative by giving the author an ability to post the SharedIt link of their paper to messaging platforms like Twitter and online community user groups such as ResearchGate, Facebook or LinkedIn.

In today's online world, massive inter-connectedness and instantaneous/straightforward access, are two features that influence the efficiency of transmission of scientific information, both to their primary intended research audience, and beyond that, to the general public. In general, this transmission efficiency is measured by article impact, which can be preguesstimated by submitting the article to a journal of a defined average impact factor or post-calculated, based on the use of citation data specific for the particular published article (Garfield 2006). Interestingly, this post-calculation can be normalised with respect to the average journal impact factor and author number, to determine the author's personal impact (Seglen 1997). However, irrespective of the type of quantitative method adopted, for reasons relating to increased funding opportunities and enhanced job security, most authors wish to raise their articles' impact within their field and also achieve recognition within the public sphere (Lawrence 2007). Through the implementation of the SharedIt programme, the Biophysical Reviews' Editorial Board, together with our commercial partner Springer Nature, are helping to maximise authors' exposure to novel media platforms, as well as giving readers around the world every possible chance to access the contents of the journal.

Acknowledgments The author would like to acknowledge Dr. Nami Hirota, Prof. Cris dos Remedios and Dr. Thijs van Vlijmen for providing comments on an early version of this Editorial.

\section{Compliance with ethical standards}

Conflict of interest Damien Hall declares that he has no conflict of interest in any commercial matter related to the content of this article.

\section{References}

Garfield E (2006) The history and meaning of the journal impact factor. JAMA 295:90-93

Lawrence PA (2007) The mismeasurement of science. Curr Biol 17(15): R583-R585

Seglen PO (1997) Why the impact factor of journals should not be used for evaluating research. BMJ 314:498-502

Shiller RJ (2014) Speculative asset prices. Nobel prize in economics acceptance speech. Nobel Foundation 